\title{
Delays in the diagnosis of uveal melanoma and effect on treatment
}

\begin{abstract}
Purpose To investigate the mode of presentation of uveal melanomas, delays in their diagnosis and the effect of delayed diagnosis on treatment outcome.

Methods An analysis was carried out of $\mathbf{5 0}$ consecutive patients undergoing treatment for uveal melanoma at the Ocular Oncology Service in Liverpool. The mode of presentation of the tumour, onset of symptoms and subsequent management were determined by interview at the time of treatment.

Results Seventy-two per cent of patients had one or more symptoms directly attributable to the tumour. These included blurred vision $(36 \%)$, photopsia $(22 \%)$, visual field loss $(16 \%)$, floaters (4\%) and metamorphopsia (4\%).

Forty-two per cent of patients experienced delays in the diagnosis and treatment due to misdiagnoses such as macular degeneration and naevus or due to the lesion being missed at the initial visit. Patients who had experienced delays in diagnosis received treatment after a mean of 6.6 months compared with 4.2 weeks for those who did not experience any delay $(p=0.003)$. Such patients were more likely to be treated by enucleation $(52 \%$ vs $17 \%, p=0.008)$ than by an eyeconserving method such as radiotherapy or trans-scleral local resection.

Conclusions The primary aim of treatment of uveal melanoma is to reduce the risk of death from metastases and a secondary aim is to conserve the eye with as much vision as possible. This study identifies common reasons for delays in the diagnosis of uveal melanoma. While the effect of early treatment on survival remains controversial, this study shows that patients who have their tumours diagnosed promptly are more likely to be treated by an eye-conserving method than by enucleation.
\end{abstract}

Key words Uveal melanoma, Delayed diagnosis, Enucleation, Local resection, Radiotherapy

Uveal melanoma is a rare but highly malignant tumour of the eye. Depending on the size of the tumour and its characteristics, up to $50 \%$ of patients eventually die of distant metastases. ${ }^{1}$ The primary aim of treatment is to reduce the threat to life and, if possible, to conserve the eye with as much vision as possible. At the Ocular Oncology Service in Liverpool, ruthenium plaque radiotherapy is currently the treatment of choice, but is only suitable for small tumours up to $5 \mathrm{~mm}$ thick. ${ }^{2}$ Proton beam radiotherapy is associated with greater side-effects and is usually reserved for small tumours that are difficult to treat with plaque radiotherapy. ${ }^{3}$ Trans-scleral local resection ${ }^{4}$ and endoresection ${ }^{5}$ are difficult techniques that require hypotensive anaesthesia. Tumours tend to be unsuitable for any form of conservative treatment if they (a) are greater than $15 \mathrm{~mm}$ in diameter, (b) invade the optic nerve or (c) show extensive involvement of the angle or ciliary body. Such tumours are usually treated by enucleation. As both survival and visual prognosis may depend on tumour size, early diagnosis and treatment are of vital importance. ${ }^{6}$

In 1996, this unit reported on delays in the diagnosis of uveal melanoma in the United Kingdom and found that the average time from the onset of symptoms or detection of an abnormality to referral to an oncologist was 6 months. ${ }^{7}$ The present study aims at identifying the reasons for delays in diagnosis and at assessing their effect on the method of treatment.

\section{Patients and methods}

We studied 50 consecutive patients seen over a 4 month period in 1996 at the Ocular Oncology Service in Liverpool and treated for uveal melanoma. Patients with suspicious naevi or other intraocular tumours were excluded. Patients were interviewed at the time of their primary treatment at St Paul's Eye Unit and specific questions were asked about (a) the onset of ocular symptoms, (b) initial presentation to a practitioner, (c) diagnosis and (d) subsequent management. The chi-squared test was used to analyse categorical data and the Mann-Whitney $U$-test to analyse nonparametric continuous data.

\section{Results}

The 50 patients ( 27 male, 23 female) had a mean age of 59.7 years at the time of treatment (range 26.4-82.0 years). At initial presentation,
F.G. Ah-Fat

B.E. Damato

St Paul's Eye Unit

Royal Liverpool University Hospital

Liverpool, UK

Mr Frank G. Ah-Fat, FRCOphth $8 Z$ Link

St Paul's Eye Unit Royal Liverpool University Hospital

Prescot Street

Liverpool L7 8XP, UK

Tel: +44(0)151706 2000, ext 3973

Fax: +44 (0)1517065861 
Table 1. Effect of delays in diagnosis on the treatment of uveal melanoma

\begin{tabular}{|c|c|c|c|}
\hline & \multirow[b]{2}{*}{ Average time to treatment } & \multicolumn{2}{|c|}{ Treatment } \\
\hline & & Enucleation & Local treatment $^{\mathrm{a}}$ \\
\hline Prompt diagnosis & $\begin{array}{c}4.2 \text { weeks } \\
\text { (range: } 10.0 \text { days to } 5.1 \text { months) }\end{array}$ & 5 & 24 \\
\hline Delayed diagnosis & $\begin{array}{l}6.6 \text { months } \\
\text { (range: } 3.1 \text { months to } 5.2 \text { years) }\end{array}$ & 11 & 10 \\
\hline$p$ value & 0.003 (Mann-Whitney $U$-test) & \multicolumn{2}{|c|}{0.008 (chi-squared test) } \\
\hline
\end{tabular}

${ }^{a}$ Local treatment: ruthenium plaque or proton beam radiotherapy, trans-scleral local resection.

36 patients $(72 \%)$ had one or more symptoms, which included blurred vision (18), photopsia (11), visual field loss (8), floaters (2) and metamorphopsia (2). Fourteen patients $(28 \%)$ were asymptomatic and presented during the course of a routine eye test. Twenty-one patients $(42 \%)$ were identified as having experienced avoidable delays in the diagnosis of their uveal melanoma. These included 6 patients seen by an optometrist and 3 patients seen by a general practitioner, who had their tumour missed or misdiagnosed. One patient experienced a delay of 6 months due to his referral letter being mislaid. Four patients had their tumour misdiagnosed as naevus or macular degeneration by an ophthalmologist. In 3 patients diagnosed as having a suspicious naevus, no follow-up was arranged and in a further 3 patients no treatment was offered after a diagnosis of melanoma was made. One patient had his choroidal melanoma missed during a 3 year period whilst under follow-up for an epiretinal membrane.

The patients were treated by ruthenium plaque radiotherapy (17), proton beam radiotherapy (9), transscleral local resection (8) and enucleation (16). Patients who had experienced difficulties in detection or diagnosis were treated after a mean period of 6.6 months after first presentation (range 3.1 months to 5.2 years), compared with 4.2 weeks (range 10.0 days to 5.1 months) for those who had experienced no difficulties $(p=0.003$, Mann-Whitney $U$-test). Such patients were also more likely to need enucleation as opposed to radiotherapy or trans-scleral local resection. Eleven of 21 patients who had experienced delays in diagnosis underwent enucleation, compared with only 5 of 29 patients who had their tumours diagnosed promptly ( $p=0.008$, chisquared test) (Table 1). The reasons for enucleation were: tumour diameter greater than $15 \mathrm{~mm}$ (4), involvement of more than a third of the ciliary body or angle (5) and optic disc involvement (7).

\section{Discussion}

The primary aim of treatment of uveal melanoma is to reduce the risk of death from metastases. However, up to half of patients treated for uveal melanoma eventually succumb to the disease. Whilst some authors believe that prompt treatment is essential to improve the chances of survival, ${ }^{8}$ others have suggested that surgical manipulation may actually promote the dissemination of tumour cells. ${ }^{9}$ Moreover, many patients may have already developed micrometastases at the time of treatment. Whether early treatment actually improves survival therefore remains highly controversial. A secondary aim of treatment is to conserve the eye with as much vision as possible, in terms of both visual acuity and visual field. Despite the small sample size, a significant finding of this study is that patients experiencing difficulties in detection or diagnosis were more likely to be treated by enucleation than by radiotherapy or trans-scleral local resection. It is likely that patients who have initially been reassured about their symptoms and discharged eventually present a later stage in the disease when the tumour has grown considerably in size or has invaded the angle or optic disc. Such tumours are often less amenable to an eyeconserving treatment.

This study also identifies the main reasons for delay as failure to detect the tumour during ophthalmoscopy, misdiagnosis as naevus or macular degeneration and failure to follow-up a suspicious naevus. The policy of simply observing melanomas is hazardous and carries the risk of the patient developing an acutely painful eye that necessitates enucleation, as was seen in 3 patients in this study. The importance of lifelong follow-up of the suspicious naevus is also illustrated. We recorded 3 patients, discharged after a diagnosis of naevus, who returned several years later with large melanomas, two of which needed enucleation.

\section{References}

1. Diener-West M, Hawkins BS, Markowitz JA, Schachat AP. A review of mortality from choroidal melanoma. II. A metaanalysis of 5-year mortality rates following enucleation, 1966 through 1988. Arch Ophthalmol 1992;110:245-50.

2. Lommatzch PK. Results after beta-irradiation $\left({ }^{106} \mathrm{Ru}^{106} \mathrm{Ru}\right)$ of choroidal melanomas: 20 years' experience. $\mathrm{Br} \mathrm{J}$ Ophthalmol 1986;70:844-51.

3. Gragoudas ES, Seddon JM, Egan K, et al. Long-term results of proton beam irradiated uveal melanomas. Ophthalmology 1987;94:349-53.

4. Damato BE, Foulds WS. Surgical resection of choroidal melanomas. In: Ryan SJ, editor. Retina, vol. 1, 2nd ed. St Louis: CV Mosby, 1994.

5. Lee KJ, Peyman GA, Raichand S. Internal eye wall resection for posterior uveal melanoma. Jpn J Ophthalmol 1993;37:287-92.

6. Manschot WA. The natural history of uveal melanomas and its therapeutic consequences. Doc Ophthalmol 1980;50:83-99.

7. Holden R, Damato BE. Preventable delays in the treatment of intraocular melanoma in the UK. Eye 1996;10:127-9.

8. Manschot WA, van Perperzeel HA. Choroidal melanoma: enucleation or observation? A new approach. Arch Ophthalmol 1980;98:71-7.

9. Zimmerman LE, McLean IW, Foster, WD. Does enucleation of the eye containing a malignant melanoma prevent or accelerate the dissemination of tumour cells? $\mathrm{Br} \mathrm{J}$ Ophthalmol $1978 ; 62: 420-5$. 